Research Article

\title{
Prediction of Precipitation in the Western Mountainous Regions of China Using a Statistical Model
}

\author{
Yijia Hu (D), Yuan Sun, Yao Ha, Yimin Zhu, and Zhixian Luo \\ College of Meteorology and Oceanography, National University of Defense Technology, Nanjing 211101, China \\ Correspondence should be addressed to Yijia Hu; lgdxhuyijia@163.com
}

Received 18 September 2019; Revised 11 July 2020; Accepted 24 August 2020; Published 22 September 2020

Academic Editor: Eduardo García-Ortega

Copyright (c) 2020 Yijia Hu et al. This is an open access article distributed under the Creative Commons Attribution License, which permits unrestricted use, distribution, and reproduction in any medium, provided the original work is properly cited.

\begin{abstract}
During the summer in the western mountainous regions of China (WMR), the disasters such as mountain floods, landslides, and debris flows caused by heavy rain occur frequently, which often result in huge economic losses and many casualties. Therefore, it is of great significance to predict the precipitation accurately in these regions. In this paper, a statistical model is established to predict the precipitation in the WMR using the linear regression statistical method, in which the summer area-averaged precipitation anomaly in WMR is taken as the predictand and the prewinter Niño3 SST is taken as the predictor. The results of the return cross test for the historical years from 1979 to 2008 and independent sample return test from 2009 to 2018 show that this statistical model has a good performance in predicting the summer precipitation in the WMR, especially in the flood years. It has better skill in the prediction of WMR precipitation than the dynamical model SINTEX-F.
\end{abstract}

\section{Introduction}

Summer in China is a season when precipitation is most concentrated. More or less precipitation in summer often causes floods, droughts, and other natural disasters, which has large impacts on people in China and is a general concern of China's meteorological departments and the whole society. Summer precipitation in China has significant characteristics of interannual and interdecadal variation, which is significantly related with ENSO [1-5]. Many studies have regarded ENSO as an important predictor for the prediction of precipitation in China [6-9]. However, some studies show that the correlation between ENSO and precipitation in most regions of China is weak and has interdecadal variation [10-12]. In addition to ENSO, the variation in precipitation is also affected by other factors, such as snow cover over the Tibetan plateau [13], monsoon [14, 15], soil moisture [16], and sea ice [17], which makes the precipitation prediction complicated and requires a comprehensive consideration of various external forcing factors. It is a pleasant surprise that the influence of ENSO on precipitation will be amplified due to the uplift of water vapor by mountain in the western mountainous regions (WMR) on the eastern edge of the Tibetan plateau of China, such as Qinling Mountains, $\mathrm{Ta} \mathrm{Pa}$ Mountains, and Wushan Mountains [18]. Summer precipitation associated with ENSO is anchored by mountains firmly. It means that the predictability of summer precipitation in these regions has been strengthened greatly due to its close relationship with ENSO.

The Qinling Mountains, Ta Pa Mountains, and Wushan Mountains are large mountains located in the WMR. Among them, the Qinling Mountains are east-west mountains located in Shanxi Province, which are regarded as the geographical dividing line between the northeastern China and southeastern China. The altitudes of Qinling Mountains are mostly between 1000 meters and 3000 meters. The Ta Pa Mountains are the mountains in boundary region of three provinces (Shaanxi, Sichuan, and Hubei). They are in the south of the Qinling Mountains. Between the Ta Pa Mountains and Qinling Mountains lies the Han River Valley. Ta Pa Mountains are in the northwest-southeast direction, and the elevation of them is generally about 2000 meters. The Wushan Mountains are located at the border of three provinces (Hubei, Chongqing, and Hunan) and are continuous clusters of peaks in the northeast-southwest direction. The main peak 
of Wushan Mountains is located in the Chongqing Province, with an altitude of 2400 meters. Wushan Mountains are regarded as the dividing line between the second and third terrain steps of China.

Affected by the specific geological environment, the natural disaster in these mountainous regions is very active. In the rainy season, disasters such as mountain torrents, landslides, and mud-rock flows caused by rainstorm happen frequently, which always result in vast economic losses and causalities. For example, in the 10 years from 1981 to 1990, six large-scale natural disasters occurred successively in the Qinling and $\mathrm{Ta} \mathrm{Pa}$ Mountains, causing more than 4,000 deaths and 1.5 million destroyed houses. The direct economic losses reach 56 million dollars [19]. The Wushan Mountains are also suffering from severe geological disasters. According to the statistics of nearly 10 years' data, there are about 40 geological disasters occurring in the Wushan Mountains every year on average, and about 15,000 people are affected by the disasters. The direct economic losses amount to 2.8 million dollars every year. For example, due to the " 8.31 " continuous heavy rainfall in 2014, 68 geological disasters occurred. 6,548 households and 28,297 people in Wushan Mountains got affected seriously. The economic losses are about 5.6 million dollars [20]. Natural disasters have become a most important factor restraining the economic development and social progress in the WMR. Therefore, an accurate prediction of precipitation in WMR regions is necessary and of great significance for preventing disasters and reducing losses.

Prediction of summer rainfall in China is extremely challenging because of the atmospheric internal variability [21], diversity in ENSO evolution [22], and so on. The dynamical models usually have poor skills in predicting the summer rainfall in China due to its low resolution and incorrect representation of the complex terrain and some physical processes [23-26]. To address this issue, many studies use physically based statistical model to predict the summer precipitation in China and achieve good results [6]; $[8,9,24,27]$. However, most studies predict the precipitation in North China, or in Yangtze River valley, or in the whole China. No study focuses on the prediction of precipitation in WMR.

Therefore, it is necessary to develop a special statistical model which can focus on the prediction of summer precipitation in WMR. In order to do this, the characteristics of temporal and spatial variation in the summer precipitation in WMR and its relationship with ENSO are analyzed in this paper firstly. Then, a statistical prediction model is established and evaluated. The second part in this paper introduces the dataset and methods in details. The third part is the data analysis and prediction modeling. The fourth part is the comparison of results between the statistical model and a dynamical model. The last part is the conclusions and discussion.

\section{Dataset and Methods}

The dataset used in this paper includes monthly averaged precipitation data from 756 stations in China and Niño3 SST index. The precipitation dataset comes from the monthly dataset of Chinese surface climate data (V3.0) released by the National Meteorological Information Center, which contains the monthly average precipitation of 756 stations in China. It can be downloaded freely at http://www.nmic.cn/. The Niño3 SST dataset is from the climate prediction center (CPC) of National Oceanic and Atmospheric Administration (NOAA), which can be downloaded freely at https:// www.esrl.noaa.gov/psd/data/climateindices/list/.

The statistical prediction model is established using the linear regression statistical method, which can be written as

$$
Y=F(x) \text {. }
$$

Here, $Y$ is the predictand (precipitation) and $X$ is the predictor (SST and atmospheric circulation indices). The 30year data from 1979 to 2008 are used to train the statistical model. Both the return cross test for the historical years from 1979 to 2008 and the independent sample return test of 10 years from 2009 to 2018 are conducted to evaluate the performance of the statistical model.

\section{Results from the Statistical Prediction Model}

Firstly, the relationship between the summer precipitation in the WMR and ENSO is analyzed. Here, the summer refers the months from June to August (JJA). The winter refers the months from December to February (DJF). Figure 1 is the distribution of correlation coefficients between the summer precipitation and prewinter Niño3 SST index from 1979 to 2008. From Figure 1, it can be found that the summer precipitation is significantly related to the prewinter Niño3 SST in the WMR and the upper reaches of Yangtze River. There are 15 stations with correlation coefficients above $95 \%$ confidence level (the black dots in Figure 1), which are mainly distributed in the Qinling Mountains, $\mathrm{Ta} \mathrm{Pa}$ Mountains, and Wushan Mountains. The detailed information of the 15 stations is given in Table 1 . The reason for the strong positive correlation relationship has been proposed by [18]. They showed that, in the post-El Niño years, the winter SST in the Niño3 region is higher than normal, an anticyclonic circulation anomaly exits over the tropical northwest Pacific, resulting in a west and strong western Pacific subtropical high, which further leads to strong warm wet southwesterlies to the western mountains. More precipitation is generated on the windward slope of the mountains due to the topographic uplift. In the post-La Niño years, when the Niño3 SST is lower than normal in winter, it is on the contrary. ENSO has a great impact on the precipitation in the WMR through the monsoon southwesterlies as the medium, which is amplified by the topographic uplift of water vapor in monsoon southwesterlies. Therefore, the correlation between summer precipitation and prewinter Niño3 SST in WMR is more obvious than other regions in China.

The above analysis is based on the summer seasonal averaged data. If this relationship between the mountainous precipitation and ENSO is stable in an intraseasonal time scale, the further correlation analysis is needed. Figure 2 is 


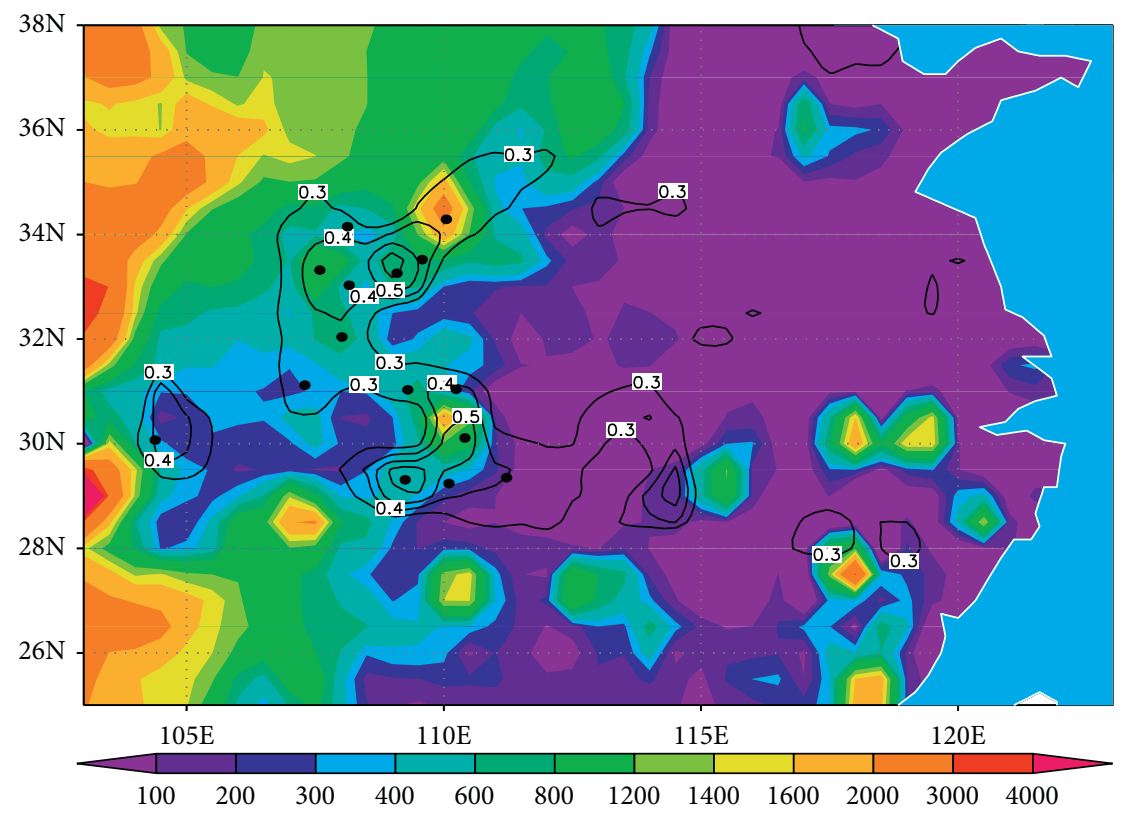

FIgURE 1: Distribution of correlation coefficients between the summer precipitation and prewinter Niño3 SST index from 1979 to 2008 . The contour lines denote the correlation coefficients above the $95 \%$ confidence level. The shaded area denotes the altitude (units: $\mathrm{m}$ ). The black dots denote the stations in the western mountainous regions with the correlation coefficients between the JJA precipitation and the prewinter Niño3 SST above 95\% confidence level.

TABLE 1: Information of stations in the western mountainous regions with correlation coefficients between the JJA precipitation and prewinter Niño3 SST index from 1979 to 2008 above the 95\% confidential level.

\begin{tabular}{lccccccc}
\hline Number & Station & Province & ID & Longitude & Latitude & Altitude (m) & Correlation coefficient \\
\hline 1 & Ziyang & Sichuan & 56298 & 104.39 & 30.07 & 357 & 0.41 \\
2 & Wugong & Shanxi & 57034 & 108.13 & 34.15 & 447.8 & 0.36 \\
3 & Huashan & Shanxi & 57046 & 110.05 & 34.29 & 2064.9 & 0.37 \\
4 & Fopin & Shanxi & 57134 & 107.59 & 33.32 & 1087.7 & 0.46 \\
5 & Shangzhou & Shanxi & 57143 & 109.58 & 33.52 & 742.2 & 0.46 \\
6 & Zhenan & Shanxi & 57144 & 109.09 & 33.26 & 693.7 & 0.60 \\
7 & Shiquan & Shanxi & 57232 & 108.16 & 33.03 & 484.9 & 0.42 \\
8 & Wanyuan & Sichuan & 57237 & 108.02 & 32.04 & 374 & 0.37 \\
9 & Daxian & Sichuan & 57328 & 107.3 & 31.12 & 310.4 & 0.36 \\
10 & Fengjie & Chongqing & 57348 & 109.3 & 31.03 & 607.3 & 0.42 \\
11 & Badong & Hubei & 57355 & 110.24 & 31.04 & 294.5 & 0.53 \\
12 & Wufeng & Hubei & 57458 & 110.41 & 30.11 & 908.4 & 0.61 \\
13 & Laifeng & Hubei & 57545 & 109.25 & 29.31 & 459.5 & 0.45 \\
14 & Sangzhi & Hunan & 57554 & 110.1 & 29.24 & 322.2 & 116.9 \\
15 & Shimen & Hunan & 57562 & 111.22 & 29.35 & & 0.39 \\
\hline
\end{tabular}

The correlation coefficient statistically significant at $95 \%$ confidence level is 0.36 .

the distribution of correlation coefficients between monthly precipitation in summer and prewinter Niño3 SST index from 1979 to 2008. It can be found from Figure 2 that the distribution of correlation coefficients changes from month to month. In June (Figure 2(a)), the significant correlation coefficients above $95 \%$ confidence level are mainly distributed in the Wushan Mountains and the upper reaches of Yangtze River, which is quite different from that in JJA (Figure 1). It indicates that the topographic uplift of the warm wet southwesterly in the WMR is not so strong in June. In July, the distribution of correlation coefficients becomes very close to that in JJA (Figure 2(b)), indicating strong orographic uplift of warm wet airflow in the WMR. In
August (Figure 2(c)), the large correlation coefficients in Wushan Mountains have disappeared and move northward to the Qinling.

The month-to-month change in the correlation between precipitation and prewinter Niño3 SST is mainly related to the intraseasonal revolution of precipitation in the WMR (Figure 3). In June (Figure 3(a)), the area with rainfall amount greater than $200 \mathrm{~mm}$ is mainly located in the Wushan Mountains. The monsoon southwesterlies have not reached Ta Pa Mountains and Qinling Mountains. The main rain belt is located in the south China. It is the preflood season in south China in June. Thus, the correlation between June precipitation and prewinter Niño3 SST is not obvious 


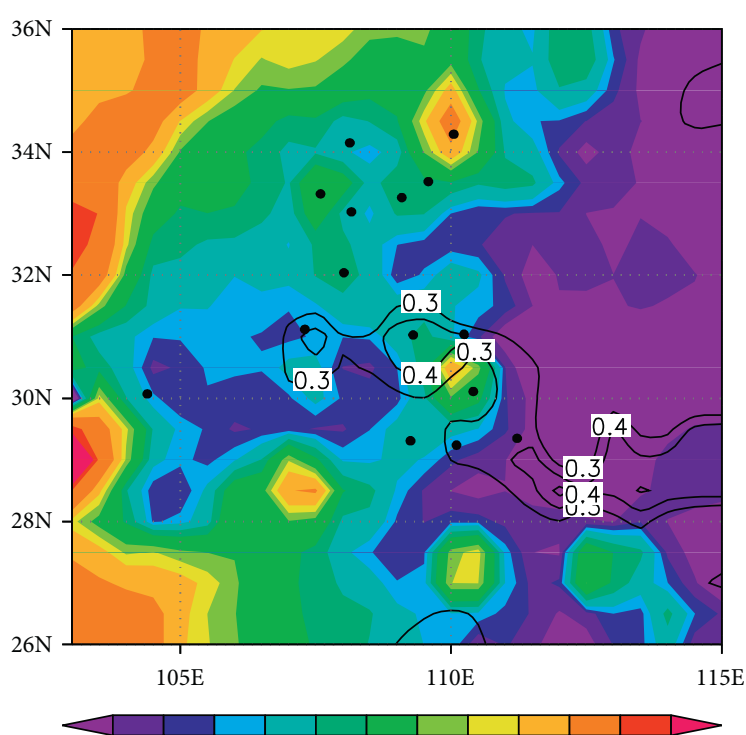

100200300400600800120014001600200030004000

(a)

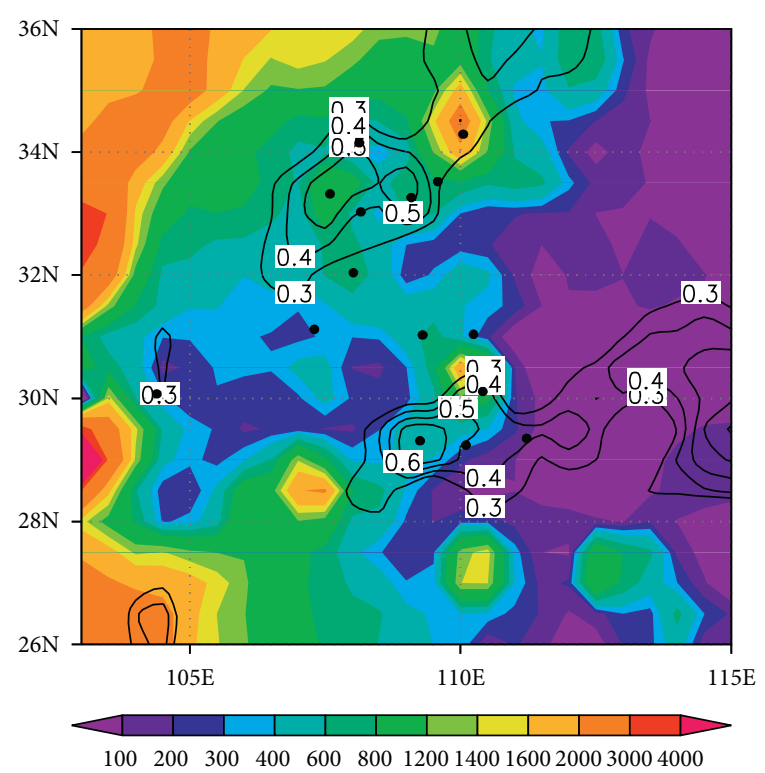

(b)

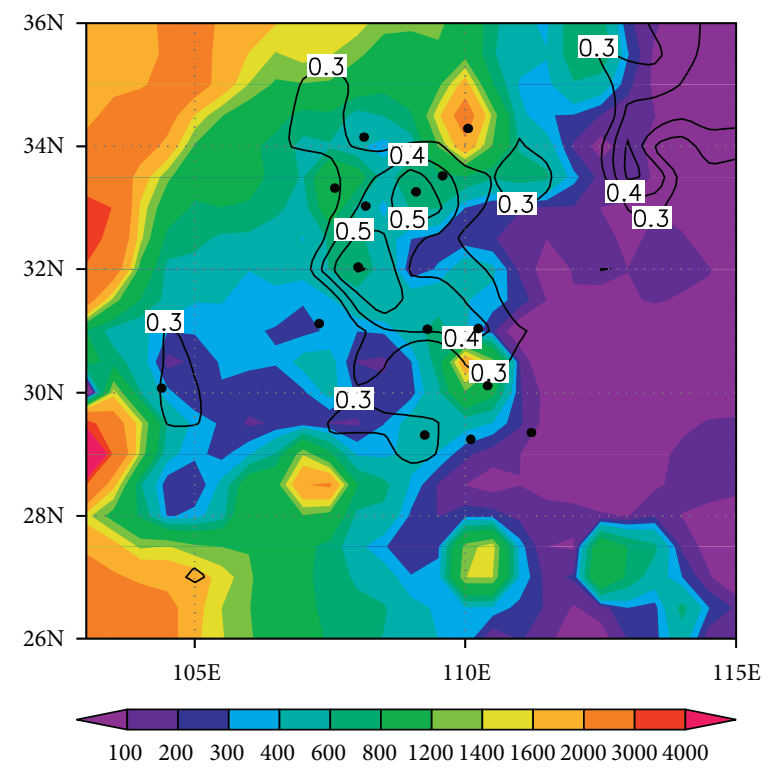

(c)

Figure 2: Distribution of correlation coefficients between monthly precipitation and prewinter Niño3 SST index from 1979 to 2008 : June (a); July (b); August (c). The contour lines denote the correlation coefficients above the $95 \%$ confidence level. The shaded area denotes the altitude (units: $\mathrm{m}$ ). The black dots denote the stations in the western mountainous region with the correlation coefficients between the JJA precipitation and the prewinter Niño3 SST above 95\% confidence level.

in Qinling Mountains and $\mathrm{Ta} \mathrm{Pa}$ Mountains. In July, the monsoon southwesterlies stretches northward to the $\mathrm{Ta} \mathrm{Pa}$ Mountains and Qinling Mountains, and the precipitation increases greatly due to the orographic lift of warm wet southwesterlies in those mountains. Therefore, the correlation between July precipitation and prewinter Niño3 SST is also significantly enhanced in this month. In August, as the monsoon advances northward further, the precipitation in Wushan Mountains decreases greatly, whereas the precipitation in Qinling Mountains and Ta Pa Mountains increases (Figure 3(c)), leading to the disappearance of large correlation coefficients in Wushan Mountains (Figure 2(c)). The significant correlation coefficients above 95\% confidence level only concentrate in Qinling Mountains, Ta Pa Mountains, parts of north China, and Taishan Mountain (Figure 2(c)). By comparing the distribution of JJA precipitation (Figure 3(d)) and the distribution of correlation coefficients between them and prewinter Niño3 SST in the WMR (Figure 1), it can be found that the distribution of large precipitation amount is basically consistent with the distribution of large correlation coefficients. The strong correlation between JJA precipitation and the ENSO is mainly caused by precipitation in July and 


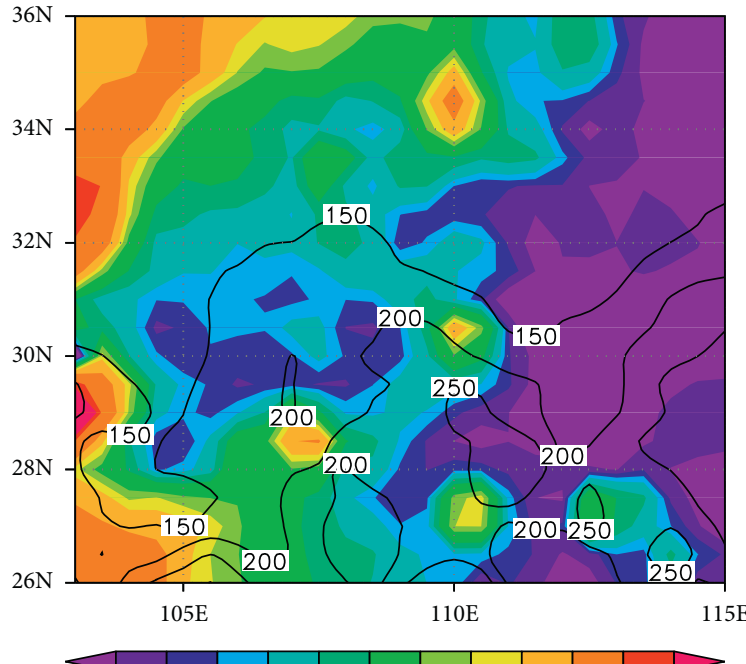

100200300400600800120014001600200030004000

(a)

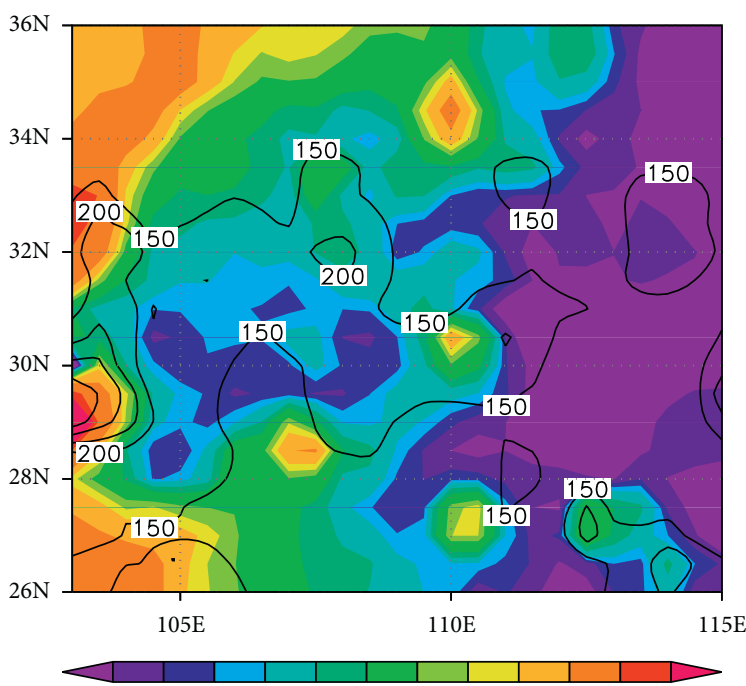

$100 \quad 200 \quad 300 \quad 400 \quad 600 \quad 800120014001600200030004000$

(c)

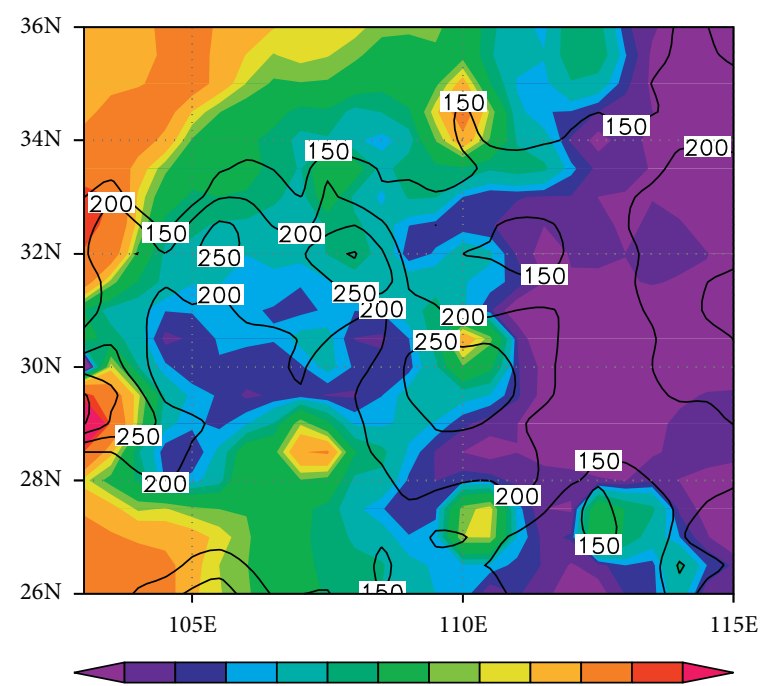

$100 \quad 200 \quad 300 \quad 400 \quad 600 \quad 800120014001600200030004000$

(b)

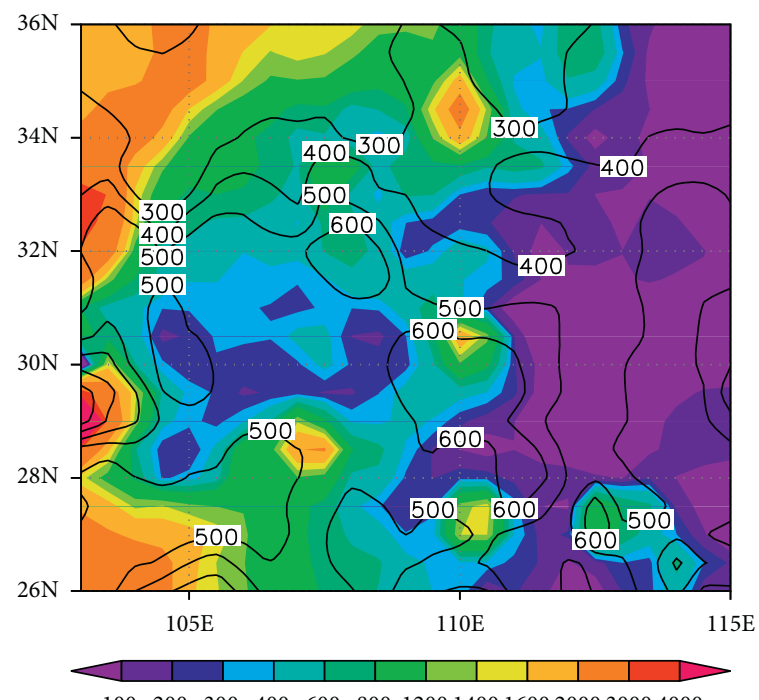

$100 \quad 200300 \quad 400 \quad 600 \quad 800 \quad 120014001600200030004000$

(d)

FIgURE 3: Distribution of rainfall amount in (a) June, (b) July, (c) August, and (d) summer (contours, units: mm) averaged from 1979 to 2008. The rainfall contours larger than $150 \mathrm{~mm}$ are drawn. The shaded area denotes the altitude (units: $\mathrm{m}$ ).

August. ENSO has great influence on the precipitation in mountainous regions through the monsoon southwesterlies as the medium. The intraseasonal variation in correlation between rainfall and ENSO is due to the combined contribution of both the orographic uplift of warm wet southwesterlies and the northward advance of the East Asian monsoon.

To establish the prediction model for the precipitation in WMR, the characteristics of the spatial and temporal variation in WMR precipitation need to be figured out. EOFs $[28,29]$ are convenient mathematical constructions to identify the basic characteristics of the precipitation in WMR. The EOF represents the spatial structure, and the principal component (PC) describes the temporal variation in the EOF. Figure 4 shows the first EOF and its corresponding $\mathrm{PC}$ of the summer precipitation anomaly based on the 15 stations data in the WMR. The variance contribution of the first EOF is $47 \%$. It can be found from Figure 4 that all the eigenvector values of the first EOF are positive, indicating that the temporal variation in precipitation of the 15 stations in the WMR is basically synchronous. Therefore, it is feasible to take the area-averaged precipitation as the predictand in the prediction of WMR precipitation.

Figure 4 also shows that the evolution of the first leading PC is very similar with the evolution of DJF Niño3 SST. They both exhibit an obvious characteristic of quasibiennial oscillation. The correlation coefficient between the first leading PC of summer precipitation in the WMR and the DJF Niño3 SST is 0.64 , which further illustrates the close relationship between the summer precipitation in WMR and ENSO.

The interdecadal variation in correlation between summer WMR precipitation and ENSO is also studied in 


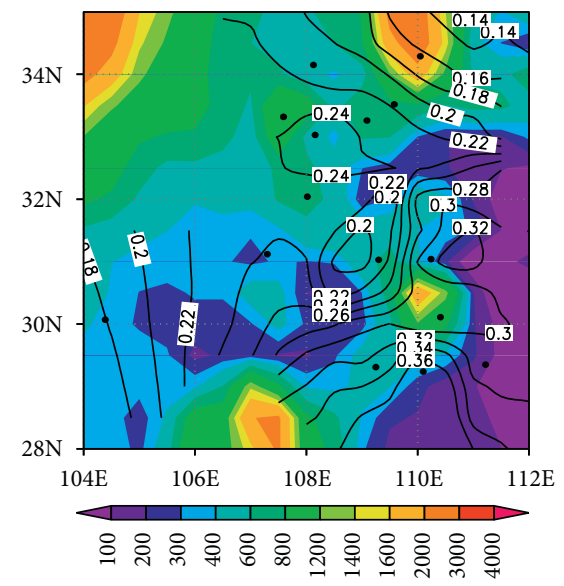

(a)

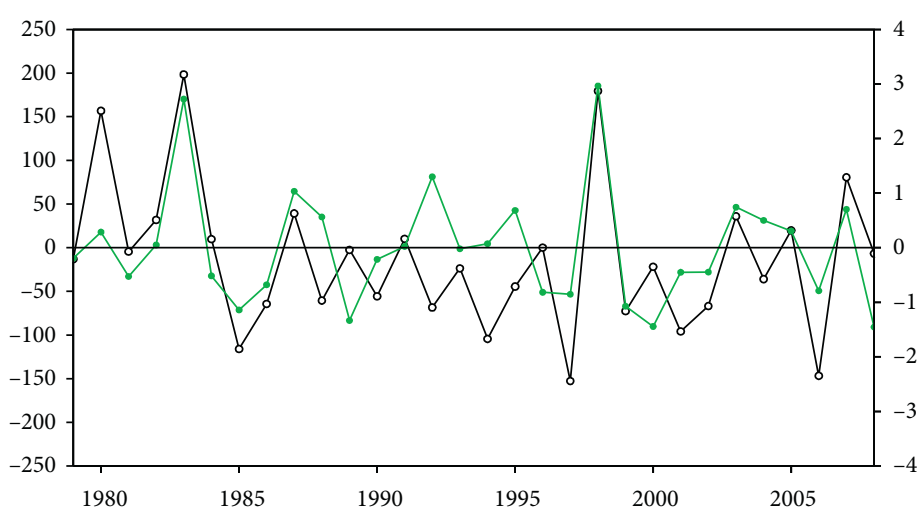

(b)

FIGURE 4: Distribution of first eigenvector (a) and principal component (b) of EOF analysis to the summer precipitation based on the 15 stations data in the western mountainous region. The variance contribution of the first eigenvector is $47 \%$.

this paper. Figure 5 shows the evolution of 21 -year slide correlation coefficients between the area-averaged summer precipitation in the WMR and the prewinter Niño3 SST. As can be seen from Figure 5, the correlation between the summer precipitation in the WMR and ENSO has an abrupt interdecadal change in 1979. Before 1979, the correlation coefficients between them are not significant. However, they become significant after 1979. Many studies have demonstrated that an interdecadal variation in precipitation in China occurred in 1979 due to the interdecadal variation in monsoon and ocean conditions [30-33]. Thus, the interdecadal variation in correlation between the summer precipitation in the WMR and ENSO has close relationship to the interdecadal variation in 1979.

To demonstrate this, the distributions of precipitation before 1979, after 1979, and difference between these two periods are analyzed (Figure 6). It can be found from Figure 6 that the precipitation in North China decreased after 1979. The precipitation in south China, the Yangtze River Basin, and the WMR increased after 1979. The precipitation in China changed from "north flood and south drought" to "north drought and south flood." With the increase in precipitation in the WMR, the uplifting effect of topography to the warm moist flow on the windward slope also becomes stronger after 1979, which makes the relationship between WMR precipitation and ENSO closer. Therefore, it is better to use the data after 1979 to establish the prediction model rather than the data before 1979 .

According to the above analysis, the 30-year data from 1979 to 2008 are used to establish the statistical model using the linear regression method. The summer area-average precipitation in the WMR is used as the predictand. The prewinter Niño3 SST index is used as predictors. The statistical model can be written as

$$
y=-1787.5+68.7 x .
$$

In this equation, $y$ is the summer area-averaged precipitation in the WMR. $x$ is the prewinter Niño3 SST index.

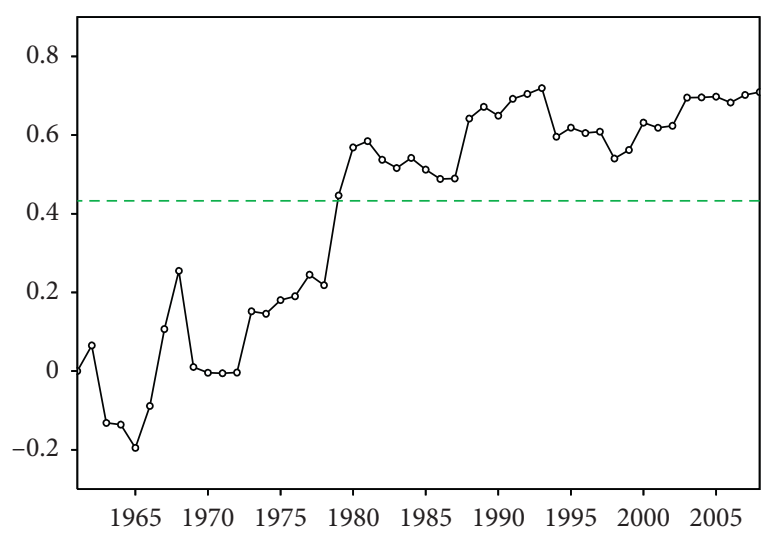

FIGURE 5: Evolution of 21-year slide correlation coefficients between the JJA precipitation in the western mountainous region and the prewinter Niño3 SST. The green dashed line denotes the significant correlation coefficient at $95 \%$ confidence level.

In order to evaluate the prediction skill of the statistical model, both the return cross test for the historical years from 1979 to 2008 and the independent sample test for the years from 2009 to 2018 are conducted. Figure 7 shows the observed and predicted summer precipitation from 1979 to 2018 in the WMR. It can be found from Figure 7 that the observed precipitation shows an obvious characteristic of interannual oscillation. The prediction model can basically reproduce the interannual variation in summer precipitation in the WMR. The correlation coefficient between predicted precipitation and the observation is 0.64 , indicating a satisfactory skill of the prediction model. However, it should also be noted that the prediction model has large bias in some years, such as 1980, 1992, 2015, and 2016, indicating that ENSO is not the only factor affecting summer precipitation in the WMR.

Table 2 shows the predicted and observed summer rainfall anomaly and relative bias of independent sample return test from 2009 to 2018 . The equation of relative bias can be written as follows: 


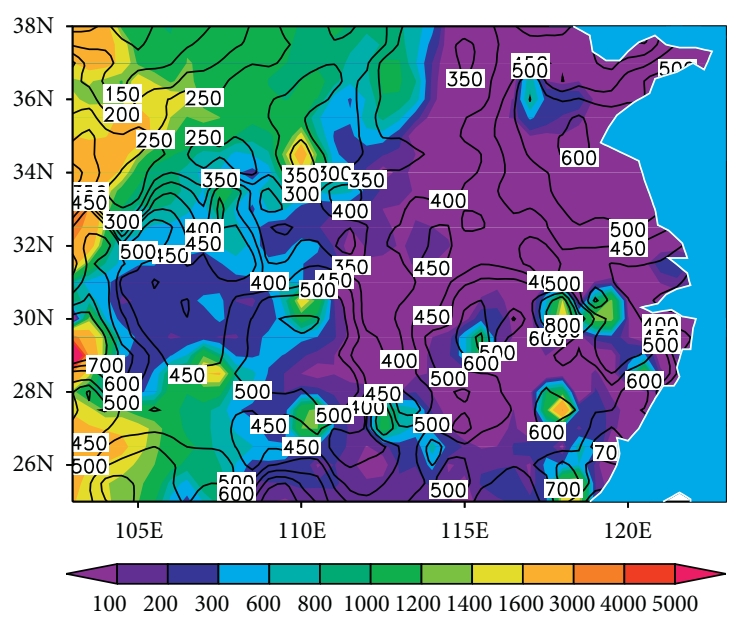

(a)

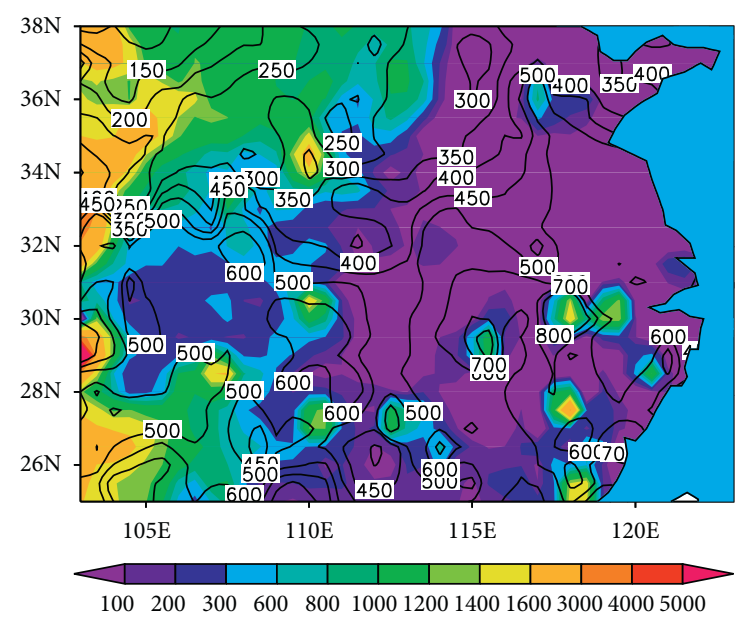

(b)

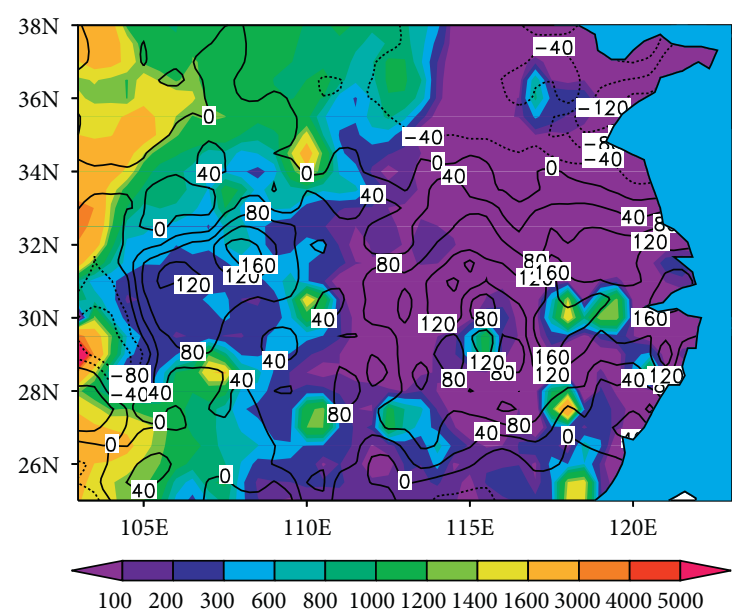

(c)

Figure 6: Distribution of the summer precipitation (units: mm) averaged from 1951 to 1979 (a), 1980-2009 (b), and the difference between two periods (1980-2009 minus 1951-1979) (c).

$$
\text { bias }=\frac{R_{p}-R_{o}}{\bar{R}_{o}} \times 100 \% .
$$

In this equation, $R_{p}$ is the predicted precipitation, $R_{o}$ is the observed precipitation, and $\bar{R}_{o}$ is the long-term mean precipitation from 1981 to 2010 . It can be seen from Table 2 that the prediction model can reproduce the precipitation anomaly in most years. The signs of the $R_{p}$ and $R_{o}$ are consistent in 9 out of 10 years, indicating a good skill of the prediction model. The relative bias is generally less than $10 \%$ in most years. If the results with an absolute value of relative bias less than $10 \%$ are counted as correct, 8 out of 10 years are correct.

However, the bias of this statistical prediction model in some years is large, which are mostly concentrated on the drought years. For example, in the years of 1988, 1992, 2006, and 2015, the observed precipitation is far less than the average climatic value, and the relative bias is large as $20.9 \%$, $31.7 \%, 27.0 \%$, and $21.3 \%$, respectively. On the contrary, the statistical model has better performance in predicting the summer precipitation during flood years than that during the drought years. The reason for this lies in that the precipitation is more than normal and the topographic uplift is stronger in the flood years, which strengthens the relationship between the summer precipitation and ENSO and the predictability of the WMR precipitation. This property of the statistical model is very helpful to reduce the losses and prevent the climatic disasters, such as mountain floods and mud-rock flows, in the flood years in western mountainous regions.

\section{Results from a Dynamical Model}

In addition to the statistical model, the ocean-atmosphere coupled general circulation models (OACGCMs) are wildly used to do the dynamical prediction of the future climate. Capturing the variation in the summer precipitation in the WMR is a notable problem. A dynamical model SINTEX-F is used to do the same prediction of WMR summer rainfall, and the results of SINTEX-F are compared with the results of the statistical model to further evaluate the performance of the statistical model. 


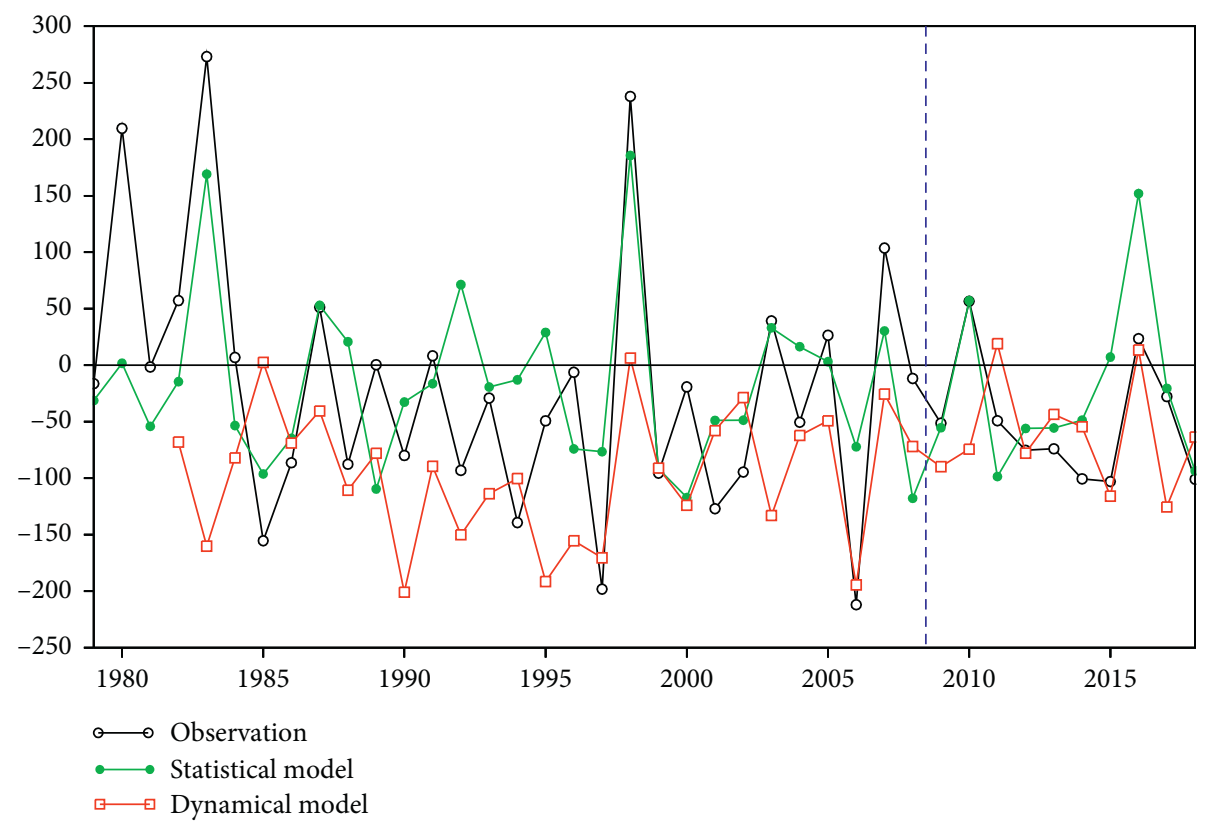

Figure 7: Observed (black line) and predicted (green line) rainfall anomaly in the western mountainous region from 1979 to 2018 (units: $\mathrm{mm}$ ). The lines before the blue dashed line denote the rainfall from the cross-validation test. The lines after the blue dashed line denote the rainfall from the independent sample test.

TABLE 2: Predicted and observed summer rainfall anomaly (units: $\mathrm{mm}$ ) and relative bias (units: 100\%) of independent sample return test from 2009 to 2018 .

\begin{tabular}{cccc}
\hline Year & Observation & Prediction & Relative bias \\
\hline 2009 & -51.3 & -57.9 & -1.3 \\
2010 & 56.6 & 42.3 & -2.8 \\
2011 & -49.2 & -98.4 & -9.5 \\
2012 & -75.3 & -42.5 & 6.3 \\
2013 & -74 & -58.2 & 3.1 \\
2014 & -100.6 & -54.4 & 8.9 \\
2015 & -103 & 22.2 & 24.2 \\
2016 & 23.5 & 156 & 25.6 \\
2017 & -27.8 & 5 & 6.3 \\
2018 & -101 & -80.6 & 3.9 \\
\hline
\end{tabular}

The SINTEX-F model is developed from Japan Marine Science and Technology Center (JAMSTEC) [34, 35], which can make seasonal-interannual forecast for the global climate. The original version of the SINTEX-F is based on the European SINTEX model under the EU-Japan collaboration project $[36,37]$. The ocean component is the reference version 8.2 of the Océan Parallélisé (OPA 8.2) [38]. Its longitude-latitude resolution is $2^{\circ} \times 2^{\circ} \cos$ (latitude) with increased meridional resolutions to $0.5^{\circ}$ near the equation. There are 31 levels in the vertical direction. The atmosphere component is ECHAM4 [39]. It adopts a high horizontal resolution (T106) of about $1.1^{\circ} \times 1.1^{\circ}$. A hybrid sigmapressure vertical coordinate is used with 19 levels. The atmosphere model and ocean model are coupled with the Océan Atmosphere Sea Ice Soil (OASIS 2.4) coupler. The initial condition of the atmosphere is provided by the $1 \mathrm{yr}$ run force with the monthly climatological SST. The ocean is started from the Levitus annual mean climatologies with zero velocities. In this study, the SINTEX-F is started at 1 March every year from 1982 to 2018, and 24 months are forecast. The results in summer are used to compare with those of the statistical model.

Figure 8 shows the distribution of correlation coefficients between the predicted summer precipitation by SINTEX-F and prewinter Niño3 SST index from 1982 to 2018. Comparing Figure 8 with Figure 1, It can be found that there are obvious differences between them. The significant positive correlation coefficients between the predicted summer precipitation by SINTEX-F and prewinter Niño3 SST index are mainly distributed in the middle and lower reaches of Yangtze River Valley, whereas the correlation coefficients are not significant in the WMR. This kind of distribution of correlation coefficients predicted by SINTEX-F is not consistent with the observation. The impacts of ENSO on the summer precipitation in the middle and lower reaches of Yangtze River Valley are magnified by the SINTEX-F. However, the relationship between the ENSO and precipitation in WMR is not be represented correctly by the SINTEX-F.

Comparing the predicted precipitation in WMR from SINTEX-F with the observation (Figure 7), it can be found that the SINTEX-F underestimates the WMR precipitation in most years. The average simulated rainfall amount from 1982 to 2018 is $431 \mathrm{~mm}$, whereas the observation is $518 \mathrm{~mm}$. The reason for this bias of SINTEX-F lies in that the resolution of the GCM is low, and it cannot represent the detailed topography in the WMR and the topographic uplift of the water vapor well. Therefore, the performance of the SINTEX-F in predicting the interannual variation in summer precipitation in the WMR is not as good as the statistical 


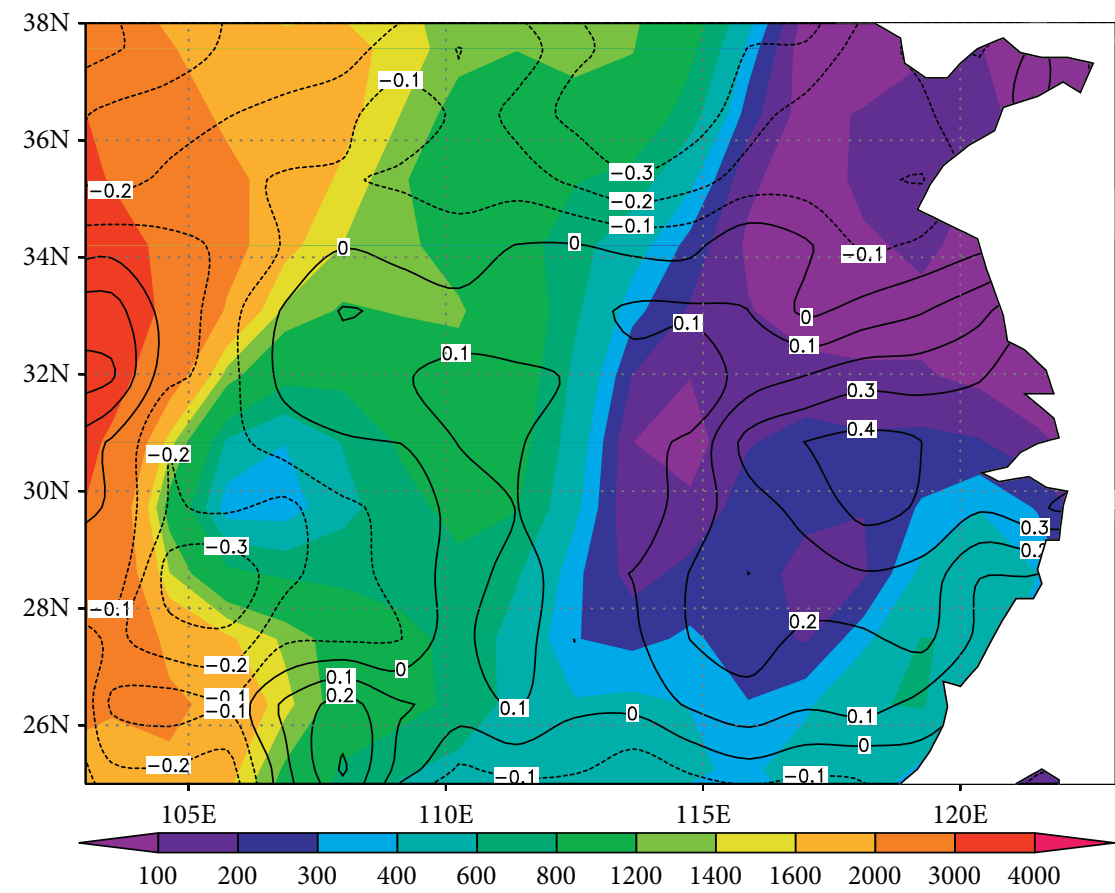

FIGURE 8: Distribution of correlation coefficients between the predicted summer precipitation by SINTEX-F and prewinter Niño3 SST index from 1982 to 2018. The contour lines denote the correlation coefficients. The shaded area denotes the model topography altitude (units: $\mathrm{m}$ ). The black dots denote the stations in the western mountainous regions with the correlation coefficients between the JJA precipitation and the prewinter Niño3 SST above 95\% confidence level.

model. The correlation coefficient between the predicted precipitation from SINTEX-F and the observation from 1982 to 2018 is 0.21 , which is much lower than that of the statistical model (0.62) and cannot pass the significance test. The root mean square error of the predicted precipitation by SINTEX-F is $155 \mathrm{~mm}$, which is larger than that of the statistical model $(72 \mathrm{~mm})$.

However, it can be noted from Figure 7 that the predictions of SINTEX-F are better than those of the statistical model in some years. The statistical model is not absolutely better than the dynamical model. Therefore, using the ensemble mean results of dynamical models and statistical models to predict the precipitation in the WMR is the recommended method.

\section{Conclusions}

Based on the observation data of 756 stations in China and Niño3 SST index, the relationship between the summer precipitation in the WMR with ENSO has been analyzed. The basic characteristics of the spatial structure and temporal variation in the summer precipitation in the WMR are analyzed using the EOFs. A statistical model is established to predict the summer precipitation in the WMR. The conclusions are as follows.

5.1. Correlation between the Summer WMR Precipitation and ENSO. It is found that the summer precipitation in the WMR has significant positive correlation with the prewinter Niño3 SST. The significant positive correlation coefficients are mainly distributed in the Qinling Mountains, Ta $\mathrm{Pa}$ Mountains, and Wushan Mountains.

The correlation between summer precipitation and ENSO in the WMR has a characteristic of intraseasonal variation, which is mainly caused by the northward advance of East Asian summer monsoon. The ENSO imposes its influence on the summer precipitation in the WMR through the summer monsoon southwesterlies as the medium. Therefore, both the northward advance of summer monsoon and the orographic uplift of the warm moist air flows result in the intraseasonal variation in the correlation between precipitation and ENSO.

The correlation of summer precipitation in the WMR and ENSO also has an obvious characteristic of interdecadal variation. The correlation between the summer WMR precipitation and ENSO is not significant before 1979, whereas it becomes significant after 1979. This interdecadal variation in correlation between summer precipitation in WMR and ENSO is related to the well-known interdecadal change of climate occur in 1979. The precipitation in the WMR increased after 1979. With the increase in precipitation in the WMR, the uplifting effect of topography to the warm moist wind on the windward slope also becomes stronger after 1979, which makes the relationship between WMR precipitation and ENSO closer.

5.2. Statistical Model. The area-averaged summer precipitation in the WMR is taken as the predictand. The prewinter Niño3 SST is used as the predictor. Then, the statistical model is established using the linear regression method. The 
results of the return cross test for the historical years from 1979 to 2008 and the independent sample test for the years from 2009 to 2018 show that this statistical model has a good performance in predicting the summer precipitation in the WMR, with low relative bias less than $10 \%$ in most years.

The good performance of this statistical model in predicting the summer precipitation in the WMR is mainly due to the stronger correlation between the WMR precipitation and ENSO than that in other regions in China. It is well known that ENSO has great impacts on the precipitation in China. However, the correlation between ENSO and precipitation in most regions of China is weak because the summer precipitation is also affected by other factors, such as snow cover over the Tibetan plateau, soil moisture, and sea ice, which makes the prediction complicated and requires a comprehensive consideration of various external forcing factors. However, in the WMR, the influence of ENSO on the WMR precipitation is amplified due to the topographic uplift of water vapor by the mountains. The statistical model can achieve good results using only prewinter Niño3 SST as the predictor. Because the ENSO often reaches its mature phase in winter, we can predict the precipitation in WMR several months in advance.

In addition, another advantage of this statistical model is that the prediction results in the rainy years are more accurate than that in the drought years. This property of the statistical model can be very helpful for reducing the losses of mountain floods, mud-rock flows, and other climatic disasters in the flood years of western mountainous region.

Compared the statistical model with the dynamic model SINTEX-F, it is found that the statistical model in this study has better performance in predicting the precipitation in the WMR. The SINTEX-F magnifies the impacts of ENSO on the precipitation in the middle and lower reaches of Yangtze River Valley and cannot represent the positive correlation between the WMR precipitation and ENSO. This defect leads to a lower skill of the SINTEX-F in predicting the WMR precipitation during summer. However, the statistical model is not absolutely superior to the dynamical model. In some years, the predicted rainfall amounts of SINTEX-F are more accurate than the statistical model in some years. Therefore, the ensemble method which can consider the advantages of both dynamical models and statistical models is recommended.

\section{Data Availability}

The precipitation dataset comes from the monthly dataset of Chinese surface climate data (V3.0) released by the National Meteorological Information Center, which contains the monthly average precipitation of 756 stations in China. It can be downloaded freely from http://www.nmic.cn/. The Niño3 SST dataset is from the climate prediction center (CPC) of National Oceanic and Atmospheric Administration (NOAA), which can be downloaded freely from https://www.esrl.noaa.gov/psd/data/climateindices/list/.

\section{Conflicts of Interest}

The authors declare that they have no conflicts of interest.

\section{Acknowledgments}

This work was sponsored jointly by the National Natural Science Foundation of China (41675077, 41975090, and 41605072), National Key Research and Development Project (2018YFC1505803 and 2018YFC1505900), Scientific Research Program of National University of Defense Technology (ZK17-03-22), and Jiangsu Collaborative Innovation Center for Climate Change.

\section{References}

[1] J. Feng, W. Chen, C.-Y. Tam, and W. Zhou, "Different impacts of El Niño and El Niño modoki on China rainfall in the decaying phases," International Journal of Climatology, vol. 31, no. 14, pp. 2091-2101, 2011.

[2] K.-M. Lau and S. Yang, "The Asian monsoon and predictability of the tropical ocean-atmosphere system," Quarterly Journal of the Royal Meteorological Society, vol. 122, no. 532, pp. 945-957, 1996.

[3] K.-M. Lau and H. Weng, "Coherent modes of global SST and summer rainfall over China: an assessment of the regional impacts of the 1997-98 El Niño," Journal of Climate, vol. 14, no. 6, pp. 1294-1308, 2001.

[4] J. Wang, J. He, X. F. Liu, and B. G. Wu, "Interannual variability of the mei-yu onset over Yangtze-Huaihe River valley and analysis of its previous strong influence signal," Chinese Science Bulletin, vol. 54, no. 4, pp. 85-92, 2009.

[5] R. Zhang and A. Sumi, "Moisture circulation over East Asia during El nino episode in northern winter, spring and autumn," Journal of the Meteorological Society of Japan, vol. 80, no. 2, pp. 213-227, 2002.

[6] K. Fan, H. Wang, and Y.-J. Choi, "A physically-based statistical forecast model for the middle-lower reaches of the Yangtze River valley summer rainfall," Chinese Science Bulletin, vol. 53, no. 4, pp. 602-609, 2008.

[7] K. Fan, M. Lin, and Y. Gao, "Forecasting the summer rainfall in North China using the year-to-year increment approach," Science in China Series D: Earth Sciences, vol. 52, no. 4, pp. 532-539, 2009.

[8] Y. Hu, Z. Zhong, Y. Zhu, and Y. Ha, "A statistical forecast model using the time-scale decomposition technique to predict rainfall during flood period over the middle and lower reaches of the Yangtze River Valley," Theoretical and Applied Climatology, vol. 132, no. 1-2, pp. 479-489, 2018.

[9] Y. Hu, Y. Zhu, Z. Zhong, and Y. Ha, "New predictors and a statistical forecast model for mei-yu onset date in the middle and lower reaches of the Yangtze river valley," Weather and Forecasting, vol. 29, no. 3, pp. 654-665, 2014.

[10] S. Shen and K.-M. Lau, "Biennial oscillation associated with the East Asian summer monsoon and tropical sea surface temperatures," Journal of the Meteorological Society of Japan. Ser. II, vol. 73, no. 1, pp. 105-124, 1995.

[11] R. Wu and B. Wang, "A contrast of the east asian summer monsoon-ENSO relationship between 1962-77 and 1978-93," Journal of Climate, vol. 15, no. 22, pp. 3266-3279, 2002.

[12] S. P. Xie, Y. Du, G. Huang et al., "Decadal shift in El Ni o influences on indo--western pacific and East Asian climate in 
the 1970s," Journal of Climate, vol. 23, no. 12, pp. 352-3368, 2010.

[13] P. Zhao, Z. Zhou, and J. Liu, "Variability of Tibetan spring snow and its associations with the hemispheric extratropical circulation and east Asian summer monsoon rainfall: an observational investigation," Journal of Climate, vol. 20, no. 15, pp. 3942-3955, 2007.

[14] D. Yihui and J. C. L. Chan, "The East Asian summer monsoon: an overview," Meteorology and Atmospheric Physics, vol. 89, no. $1-4$, pp. $117-142,2005$.

[15] B. Wang, R. Wu, and K.-M. Lau, "Interannual variability of the asian summer monsoon: contrasts between the Indian and the western north pacific-East Asian monsoons," Journal of Climate, vol. 14, no. 20, pp. 4073-4090, 2001.

[16] T. Yasunari, "Role of land-atmosphere interaction on Asian monsoon climate," Journal of the Meteorological Society of Japan, vol. 85, pp. 55-75, 2007.

[17] B. Wu, R. Zhang, B. Wang, and R. D'Arrigo, "On the association between spring Arctic Sea ice concentration and Chinese summer rainfall," Geophysical Research Letters, vol. 36, no. 9, Article ID L09501, 2009.

[18] K. Hu, S. P. Xie, and G. Huang, "Orographically-anchored El Niño effect on summer rainfall in central China," Journal of Climate, vol. 30, no. 24, pp. 10037-10045, 2017.

[19] H. Han, Z. Li, and Y. Huang, "Synthetical research on the natural disasters in Qinling and Basan areas, take the natural disaster of the Caiyuhe river basin in zhashui county, Shanxi province," Journal of Catastrophology, vol. 10, pp. 39-44, 1995, in Chinese.

[20] J. Hou and D. Gong, "To do a good job of preventing and controlling the geological disasters, and ensuring the stabilization of economic and social development in Wushan," City and Disaster Reduction, vol. 1, pp. 9-13, 2019, in Chinese.

[21] Y. Kosaka, J. S. Chowdary, S.-P. Xie, Y.-M. Min, and J.-Y. Lee, "Limitations of seasonal predictability for summer climate over East Asia and the northwestern pacific," Journal of Climate, vol. 25, no. 21, pp. 7574-7589, 2012.

[22] W. J. Zhang, F.-F. Jin, M. F. Stuecker et al., "Unraveling El nino's impact on the east Asian monsoon and Yangtze river summer flooding," Geophysical Research Letters, vol. 43, no. 21, pp. 11375-11382, 2016.

[23] B. Wang, I.-S. Kang, and J.-Y. Lee, "Ensemble simulations of Asian-Australian monsoon variability by 11 AGCMs," Journal of Climate, vol. 17, no. 4, pp. 803-818, 2004.

[24] S.-Y. Yim, B. Wang, and W. Xing, "Peak-summer East Asian rainfall predictability and prediction part II: extratropical East Asia," Climate Dynamics, vol. 47, no. 1-2, pp. 15-30, 2016.

[25] R. Yu, W. Li, Z. Huehong et al., "Climatic features related to eastern China summer rainfalls in the NCAR CCM3," Advances in Atmospheric Sciences, vol. 17, no. 4, pp. 503-518, 2000.

[26] T. Zhou, R. Yu, H. Li, and B. Wang, "Ocean forcing to changes in global monsoon precipitation over the recent half-century," Journal of Climate, vol. 21, no. 15, pp. 3833-3852, 2008.

[27] W. Xing, B. Wang, and S.-Y. Yim, "Peak-summer East Asian rainfall predictability and prediction part I: southeast Asia," Climate Dynamics, vol. 47, no. 1-2, pp. 1-13, 2016.

[28] G. R. North, T. L. Bell, R. F. Cahalan, and F. J. Moeng, "Sampling errors in the estimation of empirical orthogonal functions," Monthly Weather Review, vol. 110, no. 7, pp. 699-706, 1982.

[29] R. W. Moeng, Principal Component Analysis in Meteorology and Oceanology, Elsevier Science, Amsterdam, Netherlands, 1988.
[30] J. L. Chen and R. H. Huang, "Interannual and interdecadal variations of moisture transport by Asian summer monsoon and their association with droughts or floods in China," Chinese Journal of Geophysics, vol. 51, pp. 352-359, 2008, in Chinese.

[31] Y. Ding, Z. Wang, and Y. Sun, "Inter-decadal variation of the summer precipitation in East China and its association with decreasing Asian summer monsoon. Part I: observed evidences," International Journal of Climatology, vol. 28, no. 9, pp. 1139-1161, 2008.

[32] R. H. Huang, G. Huang, and Z. G. Wei, "Climate variations of the summer monsoon over China," in East Asian Monsoon, C. P. Chang, Ed., World Scientific, Singapore, pp. 213-270, 2004.

[33] Y. Zhu, H. Wang, W. Zhou, and J. Ma, "Recent changes in the summer precipitation pattern in East China and the background circulation," Climate Dynamics, vol. 36, no. 7-8, p. 1463, 2011.

[34] J.-J. Luo, S. Masson, S. Behera, S. Shingu, and T. Yamagata, "Seasonal climate predictability in a coupled OAGCM using a different approach for ensemble forecasts," Journal of Climate, vol. 18, no. 21, pp. 4474-4497, 2005.

[35] J.-J. Luo, S. Masson, E. Roeckner, G. Madec, and T. Yamagata, "Reducing climatology bias in an ocean-atmosphere CGCM with improved coupling physics," Journal of Climate, vol. 18, no. 13, pp. 2344-2360, 2005.

[36] S. Gualdi, A. Navarra, E. Guilyardi, and P. Delecluse, "Assessment of the tropical Indo-Pacific climate in the SINTEX CGCM," Annals of Geophysics, vol. 46, no. 1, pp. 1-26, 2003.

[37] E. Guilyardi, P. Delecluse, S. Gualdi, and A. Navarra, "Mechanisms for ENSO phase change in a coupled GCM," Journal of Climate, vol. 16, no. 8, pp. 1141-1158, 2003.

[38] G. Madec, P. Delecluse, and M. Imbard, "Ocean general circulation model reference manual," Note Ju Pnle de Modélisation, vol. 20, no. 49, p. 1563, 1997.

[39] E. Roeckner, K. Arpe, L. Bengtsson et al., "The atmospheric general circulation model ECHAM-4: model description and simulation of present-day climate," Report No. 218, MaxPlanck-Institute Für Meteorologie, Hamburg, Germany, 1996. 